\title{
Antiemetic prophylaxis against postoperative nausea and vomiting with ondansetron-dexamethasone combination compared to ondansetron or dexamethasone alone for patients undergoing laparoscopic cholecystectomy
}

\author{
Gautam B ${ }^{1}$, Shrestha $B R^{2}$, Lama $P^{3}$, Rai $S^{3}$ \\ ${ }^{1}$ Lecturer, ${ }^{2}$ Assistant professor, ${ }^{3}$ Medical Officer, Department of Anaesthesiology and Intensive Care, Kathmandu \\ Medical College, Sinamangal, Nepal.
}

\begin{abstract}
Background: Postoperative nausea and vomiting (PONV) is a common distressing experience in patients following laparoscopic surgeries. This study was aimed at comparing the efficacies of Ondansetron-Dexamethasone combination with each drug alone as a prophylaxis against PONV in patients after elective laparoscopic cholecystectomy done under general anaesthesia.

Materials and methods: Hundred and fifty ASA I and II patients, aged 23 to $65 \mathrm{yrs,} \mathrm{were} \mathrm{enrolled} \mathrm{in} \mathrm{this} \mathrm{prospective,}$ randomized, double-blind trial to receive one of three treatment regimens: $4 \mathrm{mg}$ Ondansetron (Group O), $8 \mathrm{mg}$ Dexamethasone (Group D) or $4 \mathrm{mg}$ Ondansetron plus $8 \mathrm{mg}$ Dexamethasone (Group OD) ( $\mathrm{n}=50$ for each). A standardized balanced general anaesthetic technique was employed. Any episode of PONV and need for rescue antiemetic were assessed at six, 12 and $24 \mathrm{hrs}$ post operation. Complete response was defined as no PONV in $24 \mathrm{hrs}$ and need for rescue antiemetic was considered as failure of prophylaxis. Pain scores, time to first analgesia demand, amount of Meperidine consumption, adverse event(s) and duration of hospital stay were recorded.

Results: Complete response occurred in 66.7, 66.0 and 89.4\% in Groups O, D and OD respectively. Rescue antiemetics were required in 29.2, 31.9 and $8.5 \%$ of patients in Groups O, D, and OD respectively. Significantly high incidence of vomiting and failure of prophylaxis $(19.1 \%)$ occurred in group $\mathrm{D}$ during the first six hrs $(\mathrm{P}=0.023$ versus $\mathrm{O} \& 0.008$ versus OD). More frequent antiemetic rescue was required in group $\mathrm{O}$ at 6 to $24 \mathrm{hr}$ interval as compared to group OD $(\mathrm{P}=0.032)$.

Conclusion: Combination of Ondansetron and Dexamethasone is better than each drug alone in preventing PONV after laparoscopic cholecystectomy. Dexamethasone alone is significantly less effective in preventing early vomiting compared to its combination with Ondansetron; whereas Ondansetron alone is less effective against late PONV as compared with combination therapy.
\end{abstract}

Key words: Antiemetic prophylaxis; Dexamethasone; laparoscopic cholecystectomy; Ondansetron; postoperative nausea and vomiting (PONV)

$\mathrm{T}$ he overall incidence of PONV is estimated to be around 20 to $30 \% 1$ and might peakup to $75 \%$ in certain high risk patients ${ }^{2}$. In the absence of prophylaxis 50-70\% of patients undergoing laparoscopic cholecystectomy develop $\mathrm{PONV}^{3,4}$. On top of discomfort and distress, PONV may lead to dehydration, electrolyte imbalance and subsequently delayed hospital discharge. It can also increase the risk of aspiration, wound dehiscence and prolonged wound bleeding. Patients who experience PONV consume more resources and require additional health care professional time ${ }^{5}$. PONV is also among the most unpleasant experiences associated with surgery and one of the most common reasons for poor patient satisfaction $^{6,7}$. Reduction of incidence of PONV, by utilizing various antiemetic interventions, has been shown to improve patient satisfaction and reduce the

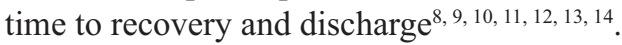

PONV can be alleviated, but not eliminated- there is no wonder drug for it. The major obstacle in solving this problem has been its multifactorial aetiology. The factors involved are not only numerous but

Correspondence

Dr. Binod Gautam

Dept. of Anaesthesiology and Intensive Care,

Kathmandu Medical College,

Sinamangal, PO Box 23760, Nepal

E-mail: gautambinod2060@hotmail.com 
also so diverse and often unavoidable such that a multipronged pharmacological approach rather than a single therapeutic agent needs to be devised to counter PONV.

Ondansetron is a 5 hydroxytryptamine type 3 receptor (5- $\mathrm{HT}_{3}$ ) antagonist that has provided effective antiemesis in surgical patients ${ }^{8,10,11,12,13,14}$. Dexamethasone is a glucocorticoid drug that has been successfully used as an antiemetic in patients undergoing chemotherapy, with limited side effects. ${ }^{15}$ It has also been evaluated and found to be effective for the prevention of PONV ${ }^{9,16,17}$. Since any single antiemetic drug has been shown to have limited efficacy against PONV, multimodal therapy has been proposed. This approach, introduced first for chemotherapy-induced nausea and vomiting is gaining popularity for PONV prophylaxis ${ }^{18}$. Most of the studies demonstrate improved prophylaxis with combination therapies ${ }^{19,20,21}$. The most commonly studied combinations have included a $5-\mathrm{HT}_{3}$ receptor antagonist with either Droperidol or Dexamethasone with comparable efficacies ${ }^{22}$.

This prospective, randomized, double-blind study was designed to compare the efficacy and safety of a single intravenous (IV) dose of combined OndansetronDexamethasone with each drug alone in the prevention of PONV in patients undergoing elective laparoscopic cholecystectomy.

\section{Material and methods}

After obtaining institutional approval and informed patient consent, we studied 150 ASA physical status I-II patients, aged between 23 and 65 years, undergoing general anaesthesia for elective laparoscopic cholecystectomy at Kathmandu Medical CollegeTeaching Hospital, Sinamangal, Kathmandu, Nepal.

Patients who had nausea and/or vomiting and/or those who had taken any antiemetic medication within $48 \mathrm{hrs}$ before surgery and those who had a history of allergy to any of the study drugs were excluded. Patients who received any investigational drug within 30 days prior to surgery as well as those who required conversion from laparoscopic technique to open approach were excluded retrospectively. Patients received diazepam 5 $\mathrm{mg}$ orally and were fasted for a minimum of $6 \mathrm{hrs}$ prior to surgery.

On arrival in the operating room, routine monitoring devices were placed, and baseline blood pressure, heart rate and pulse oximetry values were recorded. Patients were allocated randomly to receive one of three treatment regimens:

- $4 \mathrm{mg}$ Ondansetron (Group O, $\mathrm{n}=50$ ),

- $8 \mathrm{mg}$ Dexamethasone (Group D, $\mathrm{n}=50$ ) or
- $4 \mathrm{mg}$ Ondansetron plus $8 \mathrm{mg}$ Dexamethasone (Group OD, $\mathrm{n}=50$ ).

A randomization list was prepared before anaesthesia using a computer-generated random number table. Identical syringes containing each treatment regimen were diluted with normal saline to make a volume of $5 \mathrm{ml}$ by a personnel not involved in the study. Drug preparations were administered IV just before induction of anaesthesia.

Standardised anaesthetic regimen was employed for all patients. Anaesthesia was induced with $5 \mathrm{mg} \cdot \mathrm{kg}^{-1}$ Thiopentone sodium IV and $1 \mathrm{mg} \cdot \mathrm{kg}^{-1}$ Meperidine IV. Tracheal intubation was facilitated with Succinylcholine $1.5 \mathrm{mg} . \mathrm{kg}^{-1}$ IV and anaesthesia was maintained with halothane 0.75 to $2.5 \%$ in oxygen. Muscle relaxation was achieved with Norcuronium. Ventilation was mechanically controlled and was adjusted to maintain end-tidal carbon dioxide concentration at 30 to 35 $\mathrm{mmHg}$. An orogastric tube was inserted and suction applied to empty the stomach of air and other contents.

Each anticipated portal site was infiltrated with $3 \mathrm{ml}$ of $0.25 \%$ Bupivacaine by the surgeon before making a mini incision. Abdomen was insufflated with carbon dioxide $(\mathrm{CO} 2)$ at a flow rate of $0.2 \mathrm{~L} / \mathrm{min}$ and intraabdominal pressure (IAP) was maintained below 15 $\mathrm{mmHg}$ throughout surgery. Patients were positioned in reverse Trendelenburg position with left lateral tilt. Laparoscopic cholecystectomy was performed under video guidance with three punctures of the abdomen. At the end of the surgical procedure surgeons were encouraged to desufflate the abdomen as completely as possible. The orogastric tube was suctioned and then removed. Residual neuromuscular blockade was antagonized with $0.04 \mathrm{mg} . \mathrm{kg}^{-1}$ Neostigmine and 0.02 mg. $\mathrm{kg}^{-1}$ Atropine IV. The trachea was extubated once the patient became awake. No other sedative, analgesic or antiemetic drug was administered. The variables recorded during intraoperative period included: total amounts of Meperidine and fluids administered, durations of carbon dioxide insufflation, surgery and anaesthesia and occurrence of any hemodynamic instability.

Patients were monitored postoperatively for $24 \mathrm{hrs}$. Pain intensity scores were recorded at intervals of $2,6,12$, and 24 hours using a $10 \mathrm{~cm}$ visual analogue scale $(\mathrm{VAS})(0=$ no pain, $10=$ most severe pain $)$. First dose of analgesia was provided with Meperidine $1 \mathrm{mg} \cdot \mathrm{kg}^{-1}$ intramuscular (IM) when demanded by the patients and then followed by every eight hrs regimen or as demanded by the patients. Further analgesia was omitted if the patient was over sedated or pain free $(<3$ on VAS). The time interval from extubation to 
the first administration of Meperidine was recorded as the time for first Meperidine demand. The total $24 \mathrm{hr}$ consumption of Meperidine was also recorded.

While they were in the post anaesthesia care unit (until $6 \mathrm{hrs}$ after operation) and in the ward (12 and $24 \mathrm{hrs}$ post operation) the occurrence of PONV was recorded using the following numeric scale based on the patients' complaints:

- $0=$ no nausea or vomiting

- 1 = nausea only

- 2 = retching and/or vomiting.

All observations were recorded by direct questioning (with only two possible answers of yes/no) by trained on-duty doctors blinded to the group assignment, or based on spontaneous complaint by the patients. The primary end point was a "complete response", defined as no episode of PONV during the first $24 \mathrm{hrs}$ after recovery from anaesthesia. Nausea was defined as the subjectively unpleasant sensation associated with an awareness of the urge to vomit. Vomiting was defined as the forceful expulsion of gastric contents from the mouth. Retching was defined as the laboured, spasmic, rhythmic contraction of the respiratory muscles without the expulsion of gastric content ${ }^{7}$. Retching was not assessed as a separate entity and was classified under vomiting.

If two PONV score-points were reached or if patients specifically demanded antiemetic treatment in the presence of nausea, rescue antiemesis was provided with increments of $10 \mathrm{mg}$ Metoclopramide IV. These patients were then injected the same drug at an interval of eight hrs. Failure of prophylaxis, considered as a need for rescue antiemetic, was recorded at six, 12 and 24 hrs. The PONV events occurring within six hrs were considered early PONV and those occurring after six hrs were considered as late PONV.

Details of any adverse event were recorded throughout the study period based on general questioning of the patients by trained on-duty doctors, or spontaneous mention by the patients, or observation by the caring nurses. Finally the duration of hospital stay for each patient was recorded.

Comparisons of incidence of PONV and need for a rescue antiemetic between groups were performed for overall study period and at different time intervals. Statistical analyses of data among the treatment groups were performed by one-way analysis of variance with Bonferroni correction for multiple comparisons, chisquared test, or Fisher's exact probability test, as appropriate. A p value of less than 0.05 was considered significant. A sample size of 50 patients per group was required to achieve a power of $0.8(\alpha=0.05)$ to detect a large difference.

\section{Results}

Out of 150 patients enrolled, eight patients required conversion to open cholecystectomy because of surgical reasons and were excluded from the study. Data obtained from the remaining 142 patients were analyzed for interpretation.

Patient characteristics and the factors related to surgery and anaesthesia did not differ between the groups (Table 1). Time to first Meperidine demand, VAS pain scores and Meperidine consumption during $24 \mathrm{hr}$ period were similar among all groups (Table 2).

Complete response occurred in $89.4 \%$ of patients who received Ondansetron-Dexamethasone combination. This was significantly higher compared to both other groups ( $\mathrm{p}=0.033$ versus $\mathrm{O}$ and 0.028 versus $\mathrm{D})$. This was achieved in $66.7 \%$ and $66.0 \%$ of patients who received single drug therapy with Ondansetron and Dexamethasone respectively (Table 3 ).

The incidence of early PONV was significantly higher in group D $(21.3 \%)$ compared to $6.3 \%$ and $2.1 \%$ of patients in groups $\mathrm{O}$ and OD respectively ( $\mathrm{p} 0.038$ versus $\mathrm{O}$ and 0.005 versus $\mathrm{OD}$ ). There was no difference in the frequency of early PONV between groups O and OD.

The overall incidence of vomiting was $19.1 \%$ in group D compared to $4.3 \%$ in group OD and $10.4 \%$ in group O. Analysis of results at various time intervals showed no difference in emesis among the groups except at zero to six hr interval when significantly higher incidence of vomiting occurred in patients who received Dexamethasone alone. At this time interval six patients $(12.8 \%)$ vomited in group D compared to none and 1 patient in groups OD and $O$ respectively (p 0.012 versus OD and 0.045 versus O) (Table 4).

Rescue antiemetic during $24 \mathrm{hr}$ was required less frequently by the patients in group $\operatorname{OD}(\mathrm{p}=0.021$ versus $\mathrm{D}$ and 0.049 versus $\mathrm{O}$ ). Only four patients $(8.5 \%)$ in group OD required rescue antiemetic compared to 14 patients $(29.2 \%)$ in group $\mathrm{O}$ and 15 patients $(31.9 \%)$ in group D during the $24 \mathrm{hr}$ study period (Table 3 ).

Need for rescue antiemetic during the first six hr was significantly high in patients who received Dexamethasone alone. (p 0.023 versus $\mathrm{O}$ and 0.008 versus $\mathrm{OD})$. At zero to six hour interval nine patients (19.1\%) in group D compared to one patient $(2.1 \%)$ in group OD and two patients $(4.2 \%)$ in group $\mathrm{O}$ required the rescue antiemetic. 
Late antiemetic rescue, defined as a need for a rescue antiemetic after $6 \mathrm{hr}$, was higher in the Ondansetron group compared to group OD $(\mathrm{p}=0.032)$, but it was similar between groups $\mathrm{O}$ and $\mathrm{D}(\mathrm{p}=0.273)$ (Table 4).

The most frequently reported adverse event during the first $24 \mathrm{hrs}$ after recovery from anaesthesia was headache followed by throat discomfort, muscle pain, dizzinessdrowsiness, abdominal distension and urinary retention (Table 5). There were no significant differences with regards to adverse events among the study groups. The duration of hospital stay among all the groups was also similar.

Table 1: Patient characteristics and surgical-anaesthetic factors; number, mean (SD)

\begin{tabular}{|c|c|c|c|}
\hline & $\mathbf{O}$ & $\mathbf{D}$ & OD \\
\cline { 2 - 4 } & $\mathrm{n}=48$ & $\mathrm{n}=47$ & $\mathrm{n}=47$ \\
\hline Age (yr) & $38.21(9.22)$ & $39.21(8.56)$ & $38.89(11.12)$ \\
\hline Sex (F/M) & $44 / 4$ & $42 / 5$ & $43 / 4$ \\
\hline Weight (kg) & $59.92(7.098)$ & $61.26(5.70)$ & $58.68(6.74)$ \\
\hline Height (cm) & $150(6)$ & $150(6)$ & $152(5)$ \\
\hline Non smoker & 28 & 26 & 26 \\
\hline History of motion sickness & 4 & 5 & 2 \\
\hline Previous PONV & 1 & 3 & 1 \\
\hline Duration of CO2 insufflation (min) & $62.63(17.49)$ & $63.09(17.55)$ & $58.06(17.62)$ \\
\hline Duration of anaesthesia (min) & 95.54 & 97.89 & $90.19(20.70)$ \\
\hline Duration of surgery (min) & $(20.62)$ & $(21.11)$ & $72.81(18.68)$ \\
\hline Intraoperative Meperidine (mg) & $60.23(7.24)$ & $61.17(6.23)$ & $59.53(6.78)$ \\
\hline Intraoperative fluid (m) & 1458 & 1525 & 1492 \\
& $(42)$ & $(38)$ & $(35)$ \\
\hline
\end{tabular}

Table 2: VAS pain scores, first Meperidine demand and Meperidine consumption; mean (range/SD)

\begin{tabular}{|c|c|c|c|c|}
\hline & & $\mathbf{O}$ & D & OD \\
\hline \multirow{4}{*}{ VAS score } & $2 \mathrm{hr}$ & $3.8(2.0-7.0)$ & $3.6(2.2-6.8)$ & $3.5(2.0-6.8)$ \\
\hline & $6 \mathrm{hr}$ & $3.2(1.9-4.6)$ & $2.7(1.9-5.2)$ & $2.8(1.2-4.8)$ \\
\hline & 12 hr & $2.3(1.3-3.8)$ & $2.0(1.2-3.9)$ & $2.1(1.0-3.8)$ \\
\hline & $24 \mathrm{hr}$ & $2.2(1.3-2.9)$ & $1.9(0.8-2.6)$ & $1.8(2.2-6.8)$ \\
\hline \multicolumn{2}{|c|}{ First Meperidine demand (min) } & $127.75( \pm 41.32)$ & $135.98( \pm 45.16)$ & $138.79( \pm 49.19)$ \\
\hline \multicolumn{2}{|c|}{24 hr Meperidine consumption (mg) } & $189.58( \pm 58.03)$ & $178.72( \pm 47.48)$ & $178.19( \pm 58.65)$ \\
\hline
\end{tabular}


Table 3: Overall (24hr) incidence of PONV and need for rescue antiemetic

\begin{tabular}{|c|c|c|c|c|}
\hline & $\mathbf{O}$ & D & OD & $\begin{array}{c}\text { Intergroup } \\
\text { P value }\end{array}$ \\
\hline Number & 48 & 47 & 47 & \\
\hline $\begin{array}{l}\text { Complete response } \\
\text { (score 0) }\end{array}$ & $\begin{array}{c}32 \\
(66.7 \%)\end{array}$ & $\begin{array}{c}31 \\
(66.0 \%)\end{array}$ & $\begin{array}{c}42 \\
(89.4 \%)\end{array}$ & $\begin{aligned} \mathrm{O} / \mathrm{D} & =1.00 \\
\mathrm{O} / \mathrm{OD} & =0.033^{*} \\
\mathrm{D} / \mathrm{OD} & =0.028^{*}\end{aligned}$ \\
\hline $\begin{array}{l}\text { Overall nausea } \\
\text { (score 1) }\end{array}$ & $11(22.9 \%)$ & $\begin{array}{c}7 \\
(14.9 \%)\end{array}$ & $\begin{array}{c}3 \\
(6.4 \%)\end{array}$ & $\begin{array}{c}\mathrm{O} / \mathrm{D}=0.807 \\
\mathrm{O} / \mathrm{OD}=0.071 \\
\mathrm{D} / \mathrm{OD}=0.730\end{array}$ \\
\hline $\begin{array}{l}\text { Overall vomiting } \\
\text { (score } 2)\end{array}$ & $\begin{array}{c}5 \\
(10.4 \%)\end{array}$ & $\begin{array}{c}9 \\
(19.1 \%)\end{array}$ & $\begin{array}{c}2 \\
(4.3 \%)\end{array}$ & $\begin{array}{c}\mathrm{O} / \mathrm{D}=0.531 \\
\mathrm{O} / \mathrm{OD}=1.00 \\
\mathrm{D} / \mathrm{OD}=0.068\end{array}$ \\
\hline Overall PONV & $\begin{array}{c}16 \\
(33.3)\end{array}$ & $\begin{array}{c}16 \\
(34.0)\end{array}$ & $\begin{array}{c}5 \\
(10.6 \%)\end{array}$ & $\begin{aligned} \mathrm{O} / \mathrm{D} & =1.00 \\
\mathrm{O} / \mathrm{OD} & =0.033^{*} \\
\mathrm{D} / \mathrm{OD} & =0.028^{*}\end{aligned}$ \\
\hline $\begin{array}{l}\text { Overall rescue } \\
\text { antiemetic need }\end{array}$ & $14(29.2 \%)$ & $15(31.9 \%)$ & $\begin{array}{c}4 \\
(8.5 \%)\end{array}$ & $\begin{aligned} \mathrm{O} / \mathrm{D} & =1.00 \\
\mathrm{O} / \mathrm{OD} & =0.049^{*} \\
\mathrm{D} / \mathrm{OD} & =0.021^{*}\end{aligned}$ \\
\hline
\end{tabular}

* The mean difference between the groups is significant at the 0.05 level.

Table 4: Incidence of nausea / vomiting / need of rescue antiemetic; comparison at different time intervals: number $(\%)$

\begin{tabular}{|c|c|c|c|c|c|}
\hline Group & $\begin{array}{c}\text { Time } \\
\text { interval (hr) }\end{array}$ & Nausea & Vomiting & PONV & $\begin{array}{c}\text { Rescue } \\
\text { Need }\end{array}$ \\
\hline \multirow{3}{*}{$\begin{array}{l}' O ' \\
(48)\end{array}$} & $0-6$ & $\begin{array}{c}2 \\
(4.2) \\
\end{array}$ & $\begin{array}{c}1 \\
(2.1) \\
\end{array}$ & $\begin{array}{c}3 \\
(6.3) \\
\end{array}$ & $\begin{array}{c}2 \\
(4.2) \\
\end{array}$ \\
\hline & $6-12$ & $\begin{array}{c}4 \\
(8.3) \\
\end{array}$ & $\begin{array}{c}1 \\
(2.1)\end{array}$ & $\begin{array}{c}5 \\
(10.4) \\
\end{array}$ & $\begin{array}{c}5 \\
(10.4) \\
\end{array}$ \\
\hline & $12-24$ & $\begin{array}{c}5 \\
(10.4) \\
\end{array}$ & $\begin{array}{c}3 \\
(6.3)\end{array}$ & $\begin{array}{c}8 \\
(16.6)\end{array}$ & $\begin{array}{c}7^{k} \\
(14.6)\end{array}$ \\
\hline \multirow{3}{*}{$\begin{array}{l}\text { 'D' } \\
(47)\end{array}$} & $0-6$ & $\begin{array}{c}4 \\
(8.5) \\
\end{array}$ & $\begin{array}{c}6^{\#} \\
(12.8) \\
\end{array}$ & $\begin{array}{c}10^{*} \\
(21.3)\end{array}$ & $\begin{array}{c}9^{\phi} \\
(19.1) \\
\end{array}$ \\
\hline & $6-12$ & $\begin{array}{c}2 \\
(4.3)\end{array}$ & $\begin{array}{c}2 \\
(4.3) \\
\end{array}$ & $\begin{array}{c}4 \\
(8.5) \\
\end{array}$ & $\begin{array}{c}4 \\
(8.5) \\
\end{array}$ \\
\hline & $12-24$ & $\begin{array}{c}1 \\
(2.1) \\
\end{array}$ & $\begin{array}{c}1 \\
(2.1) \\
\end{array}$ & $\begin{array}{c}2 \\
(4.3) \\
\end{array}$ & $\begin{array}{c}2 \\
(4.3) \\
\end{array}$ \\
\hline \multirow{3}{*}{$\begin{array}{l}\text { 'OD' } \\
(47)\end{array}$} & $0-6$ & $\begin{array}{c}1 \\
(2.1) \\
\end{array}$ & $\begin{array}{c}0 \\
(0) \\
\end{array}$ & $\begin{array}{c}1 \\
(2.1) \\
\end{array}$ & $\begin{array}{c}1 \\
(2.1) \\
\end{array}$ \\
\hline & $6-12$ & $\begin{array}{c}1 \\
(2.1)\end{array}$ & $\begin{array}{c}1 \\
(2.1)\end{array}$ & $\begin{array}{c}2 \\
(4.3) \\
\end{array}$ & $\begin{array}{c}2 \\
(4.3) \\
\end{array}$ \\
\hline & $12-24$ & $\begin{array}{c}1 \\
(2.1)\end{array}$ & $\begin{array}{c}1 \\
(2.1)\end{array}$ & $\begin{array}{c}2 \\
(4.3)\end{array}$ & $\begin{array}{c}1 \\
(2.1)\end{array}$ \\
\hline
\end{tabular}

${ }^{\phi} \mathrm{p}=0.032$ versus $\mathrm{OD}$ and 0.273 versus $\mathrm{D},{ }^{\#} \mathrm{p}=0.045$ versus $\mathrm{O}$ and 0.012 versus $\mathrm{OD}$,

$* \mathrm{p}=0.038$ versus $\mathrm{O}$ and 0.005 versus $\mathrm{OD},{ }^{\Phi} \mathrm{p}=0.008$ versus $\mathrm{OD}$ and 0.023 versus $\mathrm{O}$ 
Table 5: Adverse events and duration of hospital stay: number, mean (SD)

\begin{tabular}{|l|c|c|c|}
\hline & O & D & OD \\
\hline Headache & 3 & 3 & 4 \\
\hline Sore throat & 2 & 3 & 2 \\
\hline Muscle pain & 2 & 2 & 1 \\
\hline Dizziness/drowsiness & 2 & 1 & 1 \\
\hline Abdominal distension & 1 & 1 & 2 \\
\hline Urinary retention & 1 & 2 & 1 \\
\hline Itching & 1 & 2 & 0 \\
\hline Hypotension & 1 & 0 & 1 \\
\hline Others & 3 & 2 & 2 \\
\hline Hospital stay (hr) & $53.6(2.1)$ & $57.5(2.2)$ & $58.3(2.6)$ \\
\hline
\end{tabular}

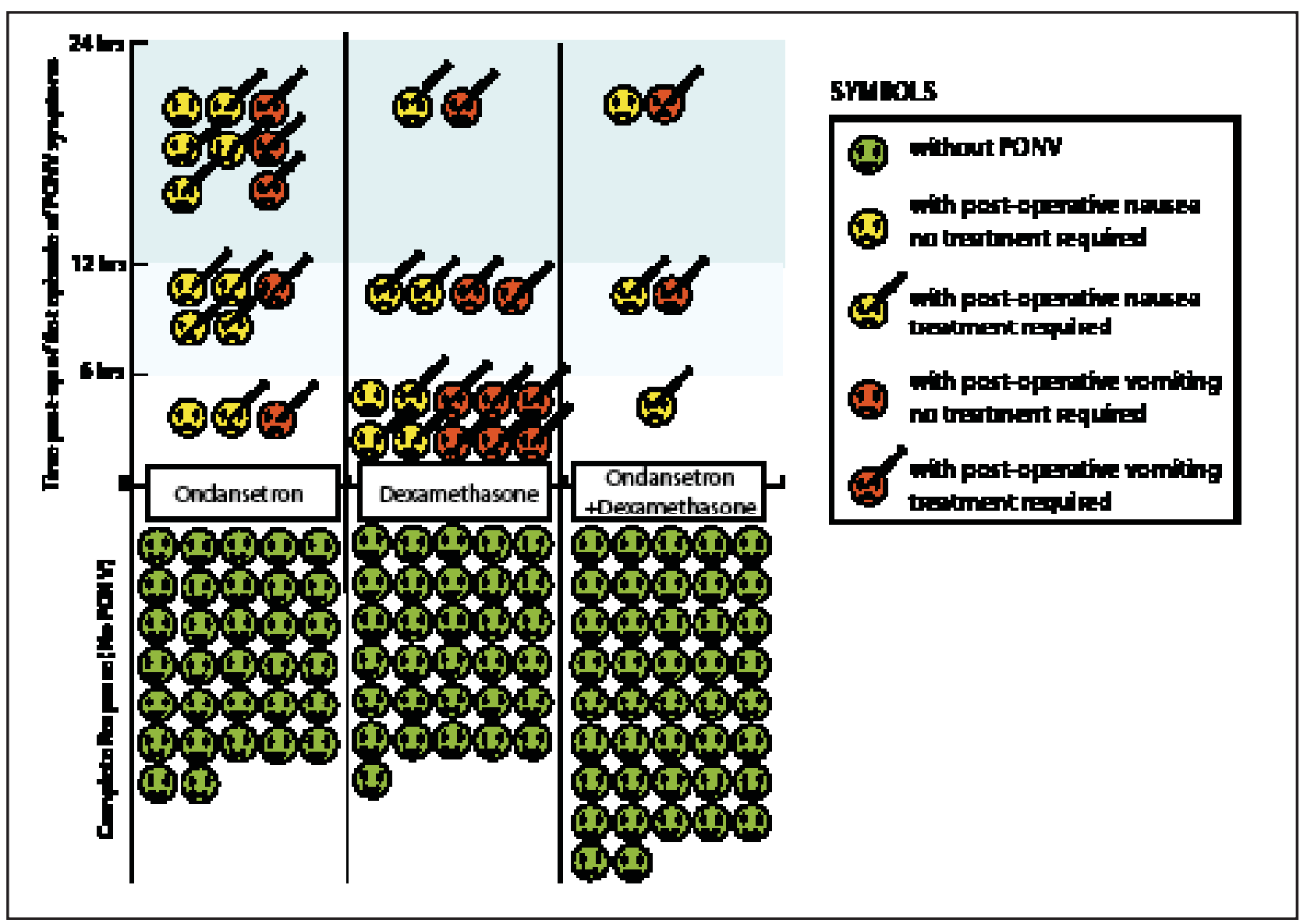

Fig 1: Incidence of PONV and need for antiemetic rescue at different time intervals 


\section{Discussion}

Laparoscopic cholecystectomy has become the treatment of choice for cholelithiasis due to its associated advantages of reduced morbidity and a shorter hospital stay ${ }^{23,24}$. The latter advantage has been negated by PONV, which is turning out to be the leading cause of unexpected re-admission after ambulatory surgery ${ }^{10}$. Patients undergoing general anaesthesia for laparoscopic cholecystectomy have a high incidence of PONV, the aetiology being multifactorial. Risk factors that have been reported to be associated with the incidence of PONV include prolonged $\mathrm{CO}_{2}$ insufflation ${ }^{3}$, residual pneumoperitoneum ${ }^{25}$, gall bladder surgery ${ }^{3}$, use of Isoflurane, Fentanyl and Glycopyrrolate ${ }^{1,7}$, intraoperative hypotension, female gender $^{1}$, nonsmoking status, history of motion sickness and PONV and postoperative use of patient-controlled analgesia with Morphine ${ }^{2,17}$. Iatrogenic nociception, or a noxious stimulus anywhere in the body might be the root cause of intraoperative genesis of PONV and a sense of malaise $\mathrm{e}^{26}$.

Here we studied the incidence of PONV in patients undergoing laparoscopic cholecystectomy and compared the occurrence of PONV in patients who received different preoperative antiemetic regimens. PONV is a recognized complication of laparoscopic cholecystectomy; therefore we did not believe it to be ethical to include a placebo arm in our study. Our selection of drug dosages was based on previous works ${ }^{12,13,16}$. The study drugs are not known to be incompatible when mixed ${ }^{27}$. The number of known risk factors, and durations of anaesthesia, surgery, and $\mathrm{CO}_{2}$ insufflation were similar among patients assigned to the three different treatment groups. Patients also received similar amounts of perioperative IV fluids and Meperidine. Therefore, we believe that differences in the incidence of PONV in the present study can be attributed to the difference in the antiemetics that were administered.

During $24 \mathrm{hrs}$ after recovery from anaesthesia, the frequencies of PONV and the need for rescue antiemetic in patients who received a combination of Ondansetron and Dexamethasone were significantly lower than those in patients who received either drug alone. As single drugs for preoperative use as antiemetics, Ondansetron and Dexamethasone were found to be equally effective. The results of our studies are in agreement with that from McKenzie and colleagues ${ }^{19}$ who have also shown lower PONV scores in the combination group. Similarly, Lopez-Olando et $a l^{21}$ have also reported higher (84\%) complete response in patients administered with Ondansetron and Dexamethasone but no significant difference in the frequencies of PONV between patients who received Ondansetron or Dexamethasone only.
Although they could not assign statistical significance Biswas et $a l^{28}$ have also reported a decreased incidence of emetic episodes in patients receiving both antiemetics compared to those receiving only one.

In this study, during the first six hrs, the incidence of vomiting and need for rescue antiemetic was significantly higher in patients who received Dexamethasone compared to both other groups. Ondansetron and Ondansetron-Dexamethasone combination were equally effective in preventing early PONV. This indicates that Dexamethasone is not particularly effective in preventing vomiting occurring early in the postoperative period. Thomas and Jones ${ }^{29}$ have shown a failure of prophylaxis during the first $3 \mathrm{hr}$ in $28.3 \%$ of patients who had received Dexamethasone compared to 22 and $8.6 \%$ of patients who had received Ondansetron and Ondansetron plus Dexamethasone respectively. Rajeeva et al $^{30}$ have demonstrated that the combination of Ondansetron and Dexamethasone provides better control of delayed PONV rather than early PONV.

In this study, in the late postoperative period (6-24 hr) patients in the Ondansetron group required more frequent antiemetic rescue compared to patients in the combination group $(\mathrm{P}=0.032)$. Although the number of patients requiring late antiemetic rescue was higher in the Ondansetron group compared to that in the Dexamethasone group, the difference was not statistically significant $(\mathrm{P}=0.273)$. This sort of late failure of prophylaxis in the Ondansetron group may have been contributed to by the shorter duration of action of Ondansetron compared to that of Dexamethasone. Similar to other 5- $\mathrm{HT}_{3}$ antagonists, Ondansetron has got a serum half-life of 4-9 $\mathrm{hrs}^{8,13,14}$. Subramaniam and Madan $^{31}$ have shown that the incidence of early PONV (0-6 hr) in children who received Dexamethasone was $24.4 \%$ compared with $17.8 \%$ in children who received Ondansetron. They also showed that the incidence of late PONV (6-24 hr) was significantly lower with Dexamethasone $(6.67 \%)$ than with Ondansetron (24.4\%). Similar findings have been reported in patients undergoing ambulatory surgery ${ }^{17,32,33}$. Dexamethasone has also been shown to provide greater protection from delayed chemotherapy-induced nausea and vomiting compared with Ondansetron ${ }^{34}$.

Corticosteroids interact with specific receptor proteins in target tissues to regulate the expression of corticosteroid-responsive genes, thereby changing the levels and array of proteins synthesized by the various target tissues. As a consequence of the time required for changes in gene expression and protein synthesis, most effects of corticosteroids are not immediate but become apparent after several hrs. The late onset and prolonged antiemetic efficacy of Dexamethasone may be attributed to its prolonged biological half-life $(36-72 \mathrm{hr})^{35}$. 
An insignificant decrease in Meperidine consumption was observed in patients who received Dexamethasone. With its strong anti-inflammatory action, Dexamethasone has been shown to decrease postoperative pain ${ }^{36}$. In our study, the time to first Meperidine administration, and pain scores were similar among patients in the three groups. Pain from multiple sources as after laparoscopic cholecystectomy may not be lessened with Dexamethasone.

There were no associated hemodynamic changes in any of the patients. The lack of difference in hospital stay or side effects among groups in our study suggests that a single dose of these study drugs is safe. Further largerscale studies and a longer follow-up are indicated.

Ondansetron is a selective 5- $\mathrm{HT}_{3}$ antagonist shown to be effective in preventing nausea and vomiting associated with cancer chemotherapy ${ }^{37}$ and radiation therapy ${ }^{38}$ as well as that occurring postoperatively $8,10,12,13,14$. The reported side effects include headache, dizziness, flushing, elevated liver enzymes and constipation.

Dexamethasone is a glucocorticoid that produces a strong antiemetic effect in preventing PONV at a recommended dose of 5 to $10 \mathrm{mg}$ in adults ${ }^{17}$. It may act through prostaglandin antagonism ${ }^{15}$, central or peripheral inhibition of serotonin ${ }^{39}$, by releasing endorphins ${ }^{40}$ and changes in the permeability of the blood CSF barrier to serum proteins ${ }^{35}$. However, there is no experimental proof to support these hypotheses.

Is an ounce of prevention worth a pound of cure? Despite the advances we have achieved in ensuring quality medical care we have still not been able to solve the seemingly simple problem of PONV which remains a major challenge and has been a perpetual dilemma since the birth of the speciality of anaesthesia and critical care medicine. PONV has long overwhelmed clinicians as a real problem. It has caused discomfort and dissatisfaction to patients across the globe. Nevertheless, little light has been shed on its aetiology during the operative period. Some patients have a history of severe PONV and some surgical procedures are almost invariably associated with PONV. So we feel justified in exploring therapeutic possibilities, even if they might not be very effective, because to do nothing seems callous, even cruel.

The obvious limitations of this study include the lack of assessment of frequency, duration and severity of nausea and vomiting. Similarly, the study was not extended beyond $24 \mathrm{hrs}$ after recovery from anaesthesia. In addition, satisfactions of the patients with regards to overall management were not assessed. Despite that it is clear from our study that patients at high risk for PONV who are treated prophylactically with combination therapy are overall less likely to require rescue antiemetics than if treated with a single agent. Larger studies that circumvent the limitations of the study are expected to allow for helping in determining the optimal regimen and timing of administration of prophylactic antiemetic therapy for different surgical scenarios and subsequently in establishing evidencebased guidelines for cost-effective therapy.

In conclusion, the combination of Ondansetron and Dexamethasone is better than each antiemetic alone as a prophylaxis against PONV following laparoscopic cholecystectomy and that Dexamethasone alone is not effective in preventing early PONV, especially vomiting. In addition, Ondansetron alone is less effective against late PONV compared to combined Ondansetron and Dexamethasone therapy.

\section{References}

1. Cohen MM, Duncan PG, DeBoer DP, Tweed WA. The postoperative interview: assessing risk factors for nausea and vomiting. Anesth Analg. 1994; 78: 7-16.

2. Apfel CC, Laara E, Koivuranta M, Greim CA. A simplified risk score for predicting PONV: conclusions from cross-validations between two centers. Anesthesiology. 1999; 91: 693-700.

3. Thune A, Appelgren L, Haglind E. Prevention of postoperative nausea and vomiting after laparoscopic cholecystectomy. Eur J Sur. 1995; 161: 265-68.

4. Iitomi T, Toriumi S, Kondo A, Akazawa T, Nakahara T. Incidence of nausea and vomiting after cholecystectomy performed via laparotomy or laparoscopy. (Japanese) Masui. 1995; 44: 1627-31.

5. Gold BS, Kitz DS, Lecky JH, Neuhaus JM. Unanticipated admission to the hospital following ambulatory surgery. JAMA. 1989; 262: 3008-10.

6. Myles PS, Williams DL, Hendrata M, Anderson H. Patient satisfaction after anaesthesia and surgery: results of a prospective survey of 10 811 patients. Br J Anaesth. 2000; 84: 6-10.

7. Watcha MF, White PF. Postoperative nausea and vomiting. Its etiology, treatment, and prevention. Anesthesiology. 1992; 77: 162-84.

8. Leeser J, Lip H. Prevention of postoperative nausea and vomiting using ondansetron, a new, selective, 5-HT3 receptor antagonist. Anesth Analg. 1991; 72: 751-5. 
9. Henzi I, Walder B, Tramer MR. Dexamethasone for the prevention of postoperative nausea and vomiting: a quantitative systematic review. Anesth Analg. 2000; 90: 186-94.

10. Liberman MA, Howe S, Lane M. Ondansetron versus placebo for prophylaxis of PONV in patients undergoing ambulatory laparoscopic cholecystectomy. Am J Surg. 2000; 179: 60-2.

11. The use of nonpharmacologic techniques to prevent postoperative nausea and vomiting: a meta-analysis. Anesth Analg. 1999; 88: 1362-9.

12. McKenzie R, Kovac A, O'Connor $\mathrm{T}$, et al. Comparision of ondansetron versus placebo to prevent postoperative nausea and vomiting in women undergoing ambulatory gynecologic surgery. Anesthesiology. 1993; 78: 21-8.

13. Pearman MH. Single dose intravenous ondansetron in the prevention of postoperative nausea and vomiting. Anaesthesia. 1994; 49(Suppl.): 11-5.

14. Koivuranta MK, Laara E, Ryhanen PT. Antiemetic efficacy of prophylactic ondansetron in laparoscopic cholecystectomy. A randomized, double-blind, placebo-controlled trial. Anaesthesia. 1996; 51: 52-5.

15. Aapro MS, Alberts DS. Dexamethasone as an antiemetic in patients treated with cisplatin (Letter). N Engl J Med. 1981; 305: 520.

16. Mokhtar Elhakim, Magdie Nafie, Khalaf Mahmoud Azza Atef. Dexamethasone $8 \mathrm{mg}$ in combination with ondansetron $4 \mathrm{mg}$ appears to be the optimal dose for the prevention of nausea and vomiting after laparoscopic cholecystectomy. Can J Anaesth. 2002; 49:9 922-926.

17. J J Wang, S T Ho, Y H Liu, et al. Dexamethasone reduces nausea and vomiting after laparoscopic cholecystectomy. Br J Anaesth. 1999; 83: $772-$ 75.

18. Smith DB, Newlands ES, Rustin GJS, et al. Comparison of ondansetron and ondansetron plus dexamethasone as antiemetic prophylaxis during cisplatin-containing chemotherapy. Lancet. 1991; 338: 487-90.

19. McKenzie R, Tantisira B, Karambelkar DJ, Riley TJ, Abdelhady H. Comparison of ondansetron with ondansetron plus dexamethasone in the prevention of postoperative nausea and vomiting. Anesth Analg. 1994; 79: 961-64.

20. Habib AS, Gan TJ. Combination therapy for postoperative nausea and vomiting-a more effective prophylaxis? Ambulatory Surgery. 2001; 9: 59-71.
21. L. Lopez-Olando, F Carrascosa, FJ Pueyo, P Monedero, N Busto, A Saez. Combination of ondansetron and dexamethasone in the prophylaxis of postoperative nausea and vomiting. Br J Anaesth. 1996; 76: 835-40.

22. Habib AS, El-Moalem HE, Gan TJ. The efficacy of the $5-\mathrm{HT}_{3}$ receptor antagonists combined with droperidol for PONV prophylaxis is similar to their combination with dexamethasone. A metaanalysis of randomized controlled trials. Can J Anesth. 2004; 51: 311-19.

23. NIH Consensus Development Panel on Gallstones and Laparoscopic Cholecystectomy. JAMA. 1993; 269: 1018-24.

24. Sandor J, Sandor A, Zaborszky A, Megyaszai S, Benedek G, Szeberin Z. Why laparoscopic cholecystectomy today? Surg Today. 1996; 26: 556-60.

25. Fredman B, Jedeikin R, Olsfanger D, Flor P, Gruzman A. Residual pneumoperitoneum: a cause of postoperative pain after laparoscopic cholecystectomy. Anesth Analg. 1994; 79: 152-4.

26. S. Rao Mallampati. Nociception is the root cause of PONV: hypothesis. Correspondence, Can J Anaesth. 2004; 51: 5; 517-18.

27. Trissel LA. Handbook of Injectable Drugs, 11th ed. Special Publishing Department of the American Society of Health-System Pharmacists, Bethesda, Maryland; 2001.

28. Biswas BN, Rudra A, Mandal SK. The prophylactic use of ondansetron with dexamethasone is more effective in preventing postoperative nausea and vomiting. J Indian Med Assoc. 2003 Nov; 101 (11): 638-42.

29. Thomas R, Jones N. Prospective randomized, double-blind comparative study of dexamethasone, ondansetron and ondansetron plus dexamethasone as prophylactic antiemetic therapy in patients undergoing day-case gynaecological surgery. Br J Anaesth. 2001; 87: 588-89.

30. Rajeeva V, Bhardwaj N, Batra YK, Dhaliwal LK. Comparison of ondansetron and dexamethasone in prevention of PONV in diagnostic laparoscopy. Can J Anaesth. 1999; 46: 40-4.

31. B Subramaniam and R Madan. Dexona is a cost-effective alternative to ondansetron in preventing postoperative nausea and vomiting after paediatric strabismus repair. Br J Anaesth. 2001; 86: 84-9. 
32. Splinter WM, Roberts DJ. Dexamethasone decreases vomiting by children after tonsillectomy. Anesth Analg. 1996; 83: 913-16.

33. Rothenberg DM, McCarthy RJ, Peng CC, Normoyle DA. Nausea and vomiting after dexamethasone versus droperidol following outpatient laparoscopy with a propofol based general anaesthetic. Acta Anaesthesiol Scand. 1998; 42: 637-42.

34. Jones A, Hill AS, Soukop M. Comparison of dexamethasone and ondansetron in the prophylaxis of emesis induced by moderately emetogenic chemotherapy. Lancet. 1991; 338: 483-87.

35. Schimmer BP, Parker KL. Adrenocorticotropic hormone-adrenocortical steroids and their synthetic analogs: inhibitors of the synthesis and actions of adrenocortical hormones. In: Goodman Gilman (Eds.). The Pharmacological Basis of Therapeutics, 9th ed. New York: McGraw Hill; 1996. 1459-85.
36. Baxendale BR, Vater $\mathrm{M}$, Lavery KM. Dexamethasone reduces pain and swelling following extraction of third molar teeth. Anaesthesia. 1993; 48: 961-64.

37. Cunningham D, Hawthorne J, Pople A, et al. Prevention of emesis in patients receiving cytoxic drugs by GR38032F, a selective 5-HT3 receptor antagonist. Lancet. 1987; 1: 1461-3.

38. Priestman TJ. Clinical studies with ondansetron in the control of radiation-induced emesis. Eur J Cancer Clin Oncol. 1989; 25 (Suppl. 1): S2933.

39. Fredrikson M, Hursti T, Furst CJ, et al. Nausea in cancer chemotherapy is inversely related to urinary Cortisol excretion. Br J Cancer. 1992; 65: 779-80.

40. Harris AL. Cytotoxic-therapy-induced vomiting is mediated via enkephalin pathways. Lancet. 1982; 1: 714-6. 